\title{
SINALIZAÇÃO DE ORIENTAÇÃO TURÍSTICA: DISCUSSÃO, NORMAS, PROPOSIÇÕES E AVALIAÇÃO DE SUA DISPOSIÇÃO: O CASO DE CURRAIS NOVOS/RN
}

TOURIST GUIDANCE SIGNS: DISCUSSION, NORMS, PROPOSITIONS AND DISPOSITION: THE CURRAIS NOVOS CASE

SEÑALIZACIÓN ORIENTACIÓNTURÍSTICA: DISCUSIÓN, NORMAS, PROPOSICIONES Y DISPOSICIÓN DE SUS EVALUACIÓN: EL CASO DE CURRAIS NOVOS/RN

\section{Francisco de Assis Lourenço do Nascimento}

Universidade Federal do Rio Grande do Norte Graduado em Turismo -UFRN francisco.I.nascimento@hotmail.com

\section{Rosana Silva de França}

Docente da Universidade Federal do Rio Grande do Norte Doutorado em Ciências Sociais - UFRN Mestre em Geografia - UFRN rosanafranca@ufrnet.br

Data de submissão: 11/05/2016

Data de aprovação: 11/08/2016

RESUMO: Neste artigo é discutido um aspecto da atividade turística que possui um número limitado de estudos que diz respeito à implantação e importância da sinalização de orientação turística. Para isso, a pesquisa discute a importância da sinalização de orientação turística, suas normas e proposições elencadas no Guia Brasileiro de Sinalização Turística. A pesquisa possui caráter teóricoempírico com abordagem metodológica que consiste na pesquisa bibliográfica, levantamento da sinalização indicativa existente com uso de geotecnologias e aplicação de formulário semiestruturado com grupos específicos de turistas e visitantes no município de Currais Novos/RN. A partir da análise 
dos sujeitos entrevistados e da disposição da sinalização no espaço urbano do município avaliase a aplicabilidade dos princípios básicos do Guia Brasileiro de Sinalização Turística e consta-se a necessidade de ampliação do número de placas de sinalização turística como um fator importante não somente para o deslocamento, mas também como elemento propulsor para a permanência e consumo de atrativos e equipamentos turísticos na região.

PALAVRAS-CHAVE: Sinalização turística; Sinalização de orientação turística; Turismo.

ABSTRACT: This article is to discuss an aspect of tourism that has a limited number of studies regarding the implementation and importance of tourist guidance signage. For this, the research discusses the importance of the tourist guidance signs, its rules and propositions listed in the Brazilian Tourist Guide Signs. The research has theoretical and empirical with methodological approach that consists of literature, survey of existing signs indicating with use of geotechnology and application of semistructured form with specific groups of tourists and visitors in the corrals municipality New / RN. From the analysis of the subjects interviewed and signaling disposal in urban areas of the municipality assesses the applicability of the basic principles of the Brazilian Guide Tourist signs and appears to need to increase the number of tourist signage boards as an important factor not only displacement, but also as a driving element for the retention and use of attractions and tourist facilities in the region.

KEYWORDS: Tourist signs; Signaling tourist orientation; Tourism.

RESUMEN: Este artículo es para discutir un aspecto del turismo que tiene un número limitado de estudios sobre la implementación y la importancia de la señalización de orientación turística. Para ello, se analiza la importancia de las señales de orientación turística, sus reglas y proposiciones que figuran en los Muestras de Guía Turística Brasileña. La investigación tiene carácter teórico y empírico con enfoque metodológico que consiste en literatura, encuesta de signos existentes indicando con uso de geotecnología y aplicación de forma semiestructurada con grupos específicos de turistas y visitantes en el municipio de Currais Novos/RN. A partir del análisis de los sujetos entrevistados y de la eliminación de señalización en las zonas urbanas del municipio se evalúa la aplicabilidad de los principios básicos de la guía turística brasileña y parece necesario incrementar el número de tableros de señalización turística como factor importante no solo de desplazamiento, También como un elemento impulsor para la retención y el uso de atracciones e instalaciones turísticas en la región.

PALABRAS CLAVE: Señalización turística; Señalización orientación turística; Turismo.

INTRODUÇÃO

apaz de influenciar na experiência turística bem como na
percepção da qualidade do destino visitado, a sinalização turística
torna-se importante tema de pesquisa. Compreender a relevância que a sinalização exerce no deslocamento do turista e o seu aproveitamento da localidade visitada pode ser utilizado como fonte de informações para a tomada de decisão pelos gestores locais. 
Sabe-se que o turismo implica no deslocamento temporário de pessoas para fora do seu local de residência habitual. Uma vez afastado do seu entorno, o ser humano começa a se deparar com locais e situações que não lhe são comuns, exigindo-se maior atenção em suas ações. Tal fato ocorre, pois, normalmente, no destino da viagem, não são encontradas as referências adquiridas na vivência diária, sendo necessário o uso de meios alternativos de auxílio ao viajante, como a sinalização turística.

A utilização da sinalização facilita o processo de apreensão dos traços marcantes da cidade, contribuindo para seu melhor aproveitamento pelo turista. Do contrário, quando esses referenciais não são supridos, a qualidade da viagem fica comprometida, podendo influenciar de forma negativa na avaliação da imagem do destino visitado.

Para Souza (2006, p. 168) a sinalização turística "está comprometida em tornar o lugar compreensível para os visitantes, explicável e passível de ser percebido individual e coletivamente." Portanto, através da sinalização, necessidades de informações que norteiem o reconhecimento espacial podem ser supridas, facilitando, assim, a orientação para o deslocamento em localidades no qual o indivíduo não esteja habituado.

Na pesquisa optamos pelo uso do termo sinalização de orientação turística, pois nota-se que há duas expressões: "sinalização turística" e "sinalização de orientação turística". A primeira é ampla e diz respeito a toda sinalização voltada ao turismo, enquanto a segunda, tema desta pesquisa, é mais restrita e referese a um tipo particular de sinalização com a finalidade de direcionar os turistas aos atrativos e demais equipamentos de interesse.

\section{PLANEJAMENTO TURÍSTICODO ESPAÇO URBANO}

A exploração da atividade turística tem sido encarada pelo poder público como uma alternativa para o desenvolvimento econômico, visando à geração e distribuição de ocupação e renda para os moradores dos municípios e regiões onde o turismo é explorado. No ano de 2004 foi lançado pelo Ministério do Turismo (MTur) o Programa de Regionalização do Turismo - Roteiros do Brasil, 
o qual tinha como objetivo diversificar a oferta turística nacional por meio do incentivo a interiorização desta atividade. Desse modo, muitos municípios e regiões do interior que apresentavam potencial para a exploração da atividade passaram a ver no turismo uma nova perspectiva econômica.

Todavia, o turismo não é viável ou desejável em todas as localidades, sendo, pois, importante verificar se o lugar onde se pretende implantar tal atividade dispõe, ou não, de recursos, tanto turísticos como técnicos e financeiros que indiquem ser viável o seu estímulo.

Conforme Bissoli (2002, p. 34)

O planejamento turístico é um processo que analisa a atividade turística de um determinado espaço geográfico, diagnosticando seu desenvolvimento e fixando um modelo de atuação mediante, objetivos, estratégias e diretrizes com os quais pretende impulsionar, coordenar e integrar o turismo ao conjunto macroeconômico em que está inserido.

Sem o planejamento turístico adequado, o estímulo ao desenvolvimento da atividade turística (feito de forma desorganizada) pode, em muitas ocasiões, potencializar efeitos negativos, como falta de segurança, poluição visual e sonora, o aumento dos preços de produtos e serviços, afetando diretamente os residentes. Desse modo, não se trata "apenas de decidir o que deve ser oferecido no futuro para uma determinada área de terra ou comunidade. $\mathrm{O}$ assunto é muito mais complexo." (Hall, 2001, p. 24).

De acordo com Marujo e Carvalho (2010), o planejamento pode ser usado em diferentes contextos geográficos (urbano e rural), bem como ser aplicado em diversas escalas (local, regional e nacional). No tocante ao turismo em área urbana, ressalta-se a importância da relação entre o planejamento turístico e planejamento do espaço urbano. Quanto a este último, Ruiz e Gandara (2013, p. 3) afirmam:

Neste, contexto, o planejamento do espaço urbano é responsável por todo o processo de idealização, criação e desenvolvimento de soluções que visam melhorar, revitalizar ou criar certos aspectos dentro de uma determinada área urbana ou região, tendo como objetivo principal proporcionar aos habitantes uma melhoria na qualidade de vida. 
Percebe-se, assim, a inter-relação do planejamento do espaço urbano com o desenvolvimento do turismo (urbano). Para que a infraestrutura turística possa ser desenvolvida de maneira eficiente (beneficiando não só turistas como também residentes, os quais podem usufruir das opções de lazer, restauração, etc.), faz-se, antes, necessário que haja infraestrutura de apoio, compreendida nos serviços de limpeza urbana, saneamento, comunicações, sinalização, etc., essenciais à vida nas cidades.

Toda cidade que pretende desenvolver a atividade do turismo deve estar planejada, organizada e orientada para receber os turistas, principalmente no que concerne ao desenvolvimento e implementação de infraestrutura e comunicação (Souza, 2006). As informações por meio da sinalização, tema do próximo tópico, otimizam o consumo de produtos e serviços turísticos, fazendo com que visitantes desfrutem de uma experiência mais intensa e recompensadora no destino da viagem.

\section{SINALIZAÇÃO E DESLOCAMENTO PELO ESPAÇO TURÍSTICO}

De acordo com o Guia Brasileiro de Sinalização Turística (EMBRATUR; IPHAN; DENATRAN, 2001), sinalização de orientação turística é:

[...] a comunicação efetuada por meio de um conjunto de placas de sinalização, implantadas sucessivamente ao longo de um trajeto estabelecido, com mensagens escritas ordenadas, pictogramas e setas direcionais. Esse conjunto é utilizado para informar os usuários sobre a existência de atrativos turísticos e de outros referenciais, sobre os melhores percursos de acesso e, ao longo destes, a distância a ser percorrida para se chegar ao local pretendido.

As informações por meio da sinalização facilitam o consumo de atrativos assim como produtos e serviços turísticos, fazendo com que visitantes desfrutem de uma experiência mais intensa e recompensadora no local visitado. Assim, como uma alternativa que visa melhorar os deslocamentos dos turistas e consequentemente a sua experiência na região de destino, a sinalização turística surge como importante ferramenta de informação e indispensável na infraestrutura turística das localidades. 
Destaca-se a necessidade de as informações turísticas terem caráter universal, atendendo desde o público regional e nacional até o internacional, por exemplo, "usuários de diferentes nacionalidades, com diversidade linguística e cultural [...] interagindo em um determinado lugar: aeroporto, centro médico, repartição pública" (Equador, 2007, p. 10). A sinalização deve se apresentar para o indivíduo como um guia de determinado local, chamando discretamente sua atenção e dando as informações necessárias de forma "instantânea" e "global".

Conforme a Organização Mundial do Turismo, evidências apontam que as primeiras formas de sinalização utilizadas para o turismo tenham surgido ainda no século XVI, mas precisamente no ano de 1552, quando o impressor da cidade de Lyon, Charles Estienne "publicou os primeiros guias cartográficos da França [...] e inventou palavras-chave e abreviações fornecendo indicações mínimas com grande precisão sobre as cidades ao longo das rotas, as distâncias entre elas, as passagens, etc." (OMT, 2003, p. 7-8).

Ouso designosemarcas parasinalizaçãotiveramgrandeevoluçãoimpulsionados pela Revolução Industrial em decorrência da expansão da malha rodoviária e ferroviária. "Antes disso, as autoridades locais, geralmente, arrecadavam taxas nas estradas, e o coletor destas atuava como guia" (OMT, 2003, p. 8).

A viagem em massa estimulou o aparecimento da sinalização em toda parte praticamente ao mesmo tempo, tanto na classificação das estradas como nas instalações turísticas (hotéis, restaurantes, etc.). Visando a padronização, em 1968, a Convenção de Signos e Sinais Rodoviários foi adotada em Viena. Em 1971, como complemento a Convenção, o Acordo Europeu contém cláusulas sobre sinais que indicam atrativos turísticos e aqueles que fornecem direção (para o turismo) (OMT, 2003).

No caso do Brasil, os responsáveis pelas primeiras iniciativas de sinalização com informações turísticas foram o CONTRAN e o DENATRAN. Estas iniciativas se deram a partir do fim da década de 1980 e ajudaram a sistematizar a sinalização no território nacional (OMT, 2003).

Pelo fato da sinalização de orientação turística fazer parte do conjunto de sinalização de indicação de trânsito, deve seguir os princípios e objetivos fundamentais dos usuários do sistema viário. Portanto, faz-se necessário 
que seja implantada visando assegurar a aplicação dos seguintes objetivos e princípios básicos (EMBRATUR; IPHAN; DENATRAN, 2001):

1) Legalidade

- Cumprir o estabelecido no Código de Trânsito Brasileiro - CTB e nas resoluções do Conselho Nacional de Trânsito - Contran.

- Cumprir a legislação de preservação de sítios tombados pelo Instituto do Patrimônio Histórico e Artístico Nacional - Iphan e protegidos pela Lei de Arqueologia.

2) Padronização

- Seguir um padrão preestabelecido quanto a: Formas e cores dos sinais; letras, tarjas, setas e pictogramas; aplicação - situações idênticas sinalizadas da mesma forma; colocação na via ou nas localidades.

3) Visibilidade, legibilidade e segurança

- Ser visualizada e lida a uma distância que permita segurança e tempo hábil para a tomada de decisão, de forma a evitar hesitação e manobras bruscas.

- Selecionar trajetos de fácil compreensão para os usuários, com o objetivo de valorizar os aspectos de interesse cultural e turístico, levando em conta a segurança do trânsito.

- Garantir a integridade dos monumentos destacados e impedir que a sinalização interfira em sua visualização.

- Resguardar as peculiaridades dos sítios.

4) Suficiência

- Oferecer as mensagens necessárias a fim de atender os deslocamentos dos usuários.

- Auxiliar a adaptação dos usuários às diversas situações viárias. 
5) Continuidade e coerência

- Assegurar a continuidade das mensagens até atingir o destino pretendido, mantendo coerência nas informações.

- Ordenar a cadência das mensagens, para garantir precisão e confiabilidade.

6) Atualidade e valorização

- Acompanhar a dinâmica dos meios urbano e rural, adequando a sinalização a cada nova realidade.

- Assegurar a valorização da sinalização, mantendo-a atualizada e buscando evitar a gerar desinformações sucessivas.

7) Manutenção e conservação

- Estar sempre conservada, limpa, bem fixada e, quando for o caso, corretamente iluminada.

Seguindo esses princípios, antes de iniciar a implantação das placas de sinalização, deve ser realizado na localidade o levantamento dos atrativos turísticos existentes, bem como as condições que oferecem para o recebimento de visitantes, em suma, trata da acessibilidade do local. O Guia também orienta que, após esta etapa, o próximo passo a ser feito seja uma análise detalhada da distribuição dos atrativos na área a ser sinalizada, buscando identificar se há concentração, dispersão, ou ambos.

Parte dos estudos da semióticaé também muito relevante para o auxílio da sinalização turística, os sistemas pictóricos (conjunto visual e gráfico de função sinalética) mostram-se essenciais no papel de identificação dos atrativos e outros pontos de interesse ao turismo.

Cabe salientar que a sinalização de orientação turística deve atender também o turismo internacional, proporcionando a acessibilidade com a adequação de placas bilíngues e disposição de aplicativos com informações de 1 A semiótica pode ser compreendida como a ciência "que tem por objeto de investigação todas as linguagens possíveis" (SANTAELLA, 2007. p. 2), entre elas a não-verbal, constituída de símbolos e signos. A tarefa da semiótica é investigar a ação e função dos signos. 
ISSN: 1983-7151

interesse turístico, e outras facilidades como a implantação códigos de barras bidimensionais, ou seja, $Q R$ Codes em pontos turísticos que rapidamente, através do uso de smarthfones e tablets, podem levar o usuário a um link com informações diversas sobre o local em questão. Diversos destinos nacionais e internacionais têm utilizado tal prática para promover a atividade turística uma vez que os manuais de sinalização turística atendem um padrão geral, mas que na prática ainda são apontados como insuficientes no atendimento de determinados atrativos e das especificidades locais. Outra prática que têm sido adotada consiste na implantação de totens de sinalização turística que consiste numa sinalização voltada para o pedestre, contendo orientações, mapa e informações de cunho histórico ou regional.

De acordo com o Guia Brasileiro de Sinalização Turística (EMBRATUR; IPHAN; DENATRAN, 2001) pictogramas correspondem às "ilustrações que sintetizam os tipos de atrativo turístico e de serviço auxiliar, cujo uso é recomendado para facilitar a identificação do destino, complementando a função do topônimo e melhorando o esquema de comunicação com o usuário", conforme mostra a figura 1.

Figura 1 - Exemplos de pictogramas utilizados na sinalização turística (Arquitetura religiosa; Monumento; Parada de ônibus).
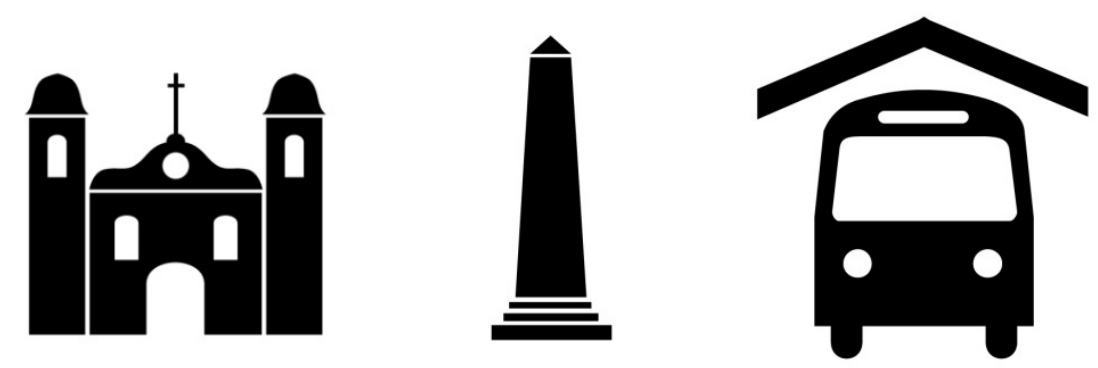

Fonte: Guia Brasileiro de Sinalização Turística, 2001.

Quando utilizados no turismo, os pictogramas devem ser de fácil identificação e o símbolo deve estar na cor preta sobre um campo na forma quadrada de cor branca. No que concerne ao tamanho, este pode variar de acordo com o tipo de placa e sua disposição na via. (EMBRATUR; IPHAN; DENATRAN, 2001)

Ao citar o Guia Brasileiro de Sinalização Turística, Scatolin et al. (2006, p. 1314) faz distinção entre dois tipos:

- Placa interpretativa - Como mostra a figura 2, são as traduções do conhecimento por meio de uma linguagem prazerosa e de fácil compreensão. 
Objetivam enriquecer a vida das pessoas, apresentando-Ihes algo em que pensar, lembrar ou explorar. Devem destacar e disseminar informações e tentar mudar comportamentos, ser atraentes e planejadas para durar, com estrutura resistente e conteúdo preciso.

Figura 2 - Placa interpretativa na entrada da Mina Brejuí, município de Currais Novos.

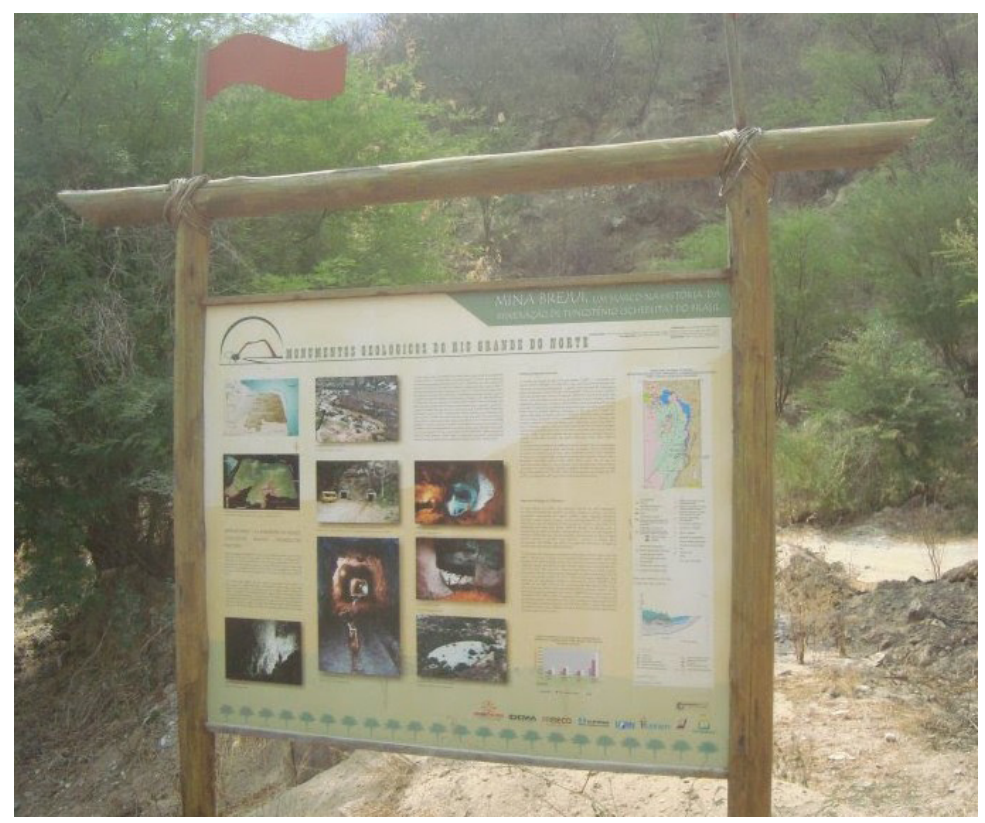

Fonte: Acervo do autor, 2011.

- Placa indicativa - As placas para pedestres indicativas devem ser fixadas em locais de distribuição de fluxos, fazendo com que o visitante consiga interagir com o local turístico. De acordo com Guia Brasileiro de Sinalização Turística (EMBRATUR; IPHAN; CONTRAN, 2001), são fundamentais no processo de informação e sensibilização do visitante, o que permite que ele se localize com facilidade e realize o maior número possível de deslocamentos a pé e em roteiro de visitação estruturada. A figura 3 mostra um exemplo de placa indicativa.

Figura 3: Modelo de placa indicativa de sentido

\section{uㅐ Véu de Noiva}

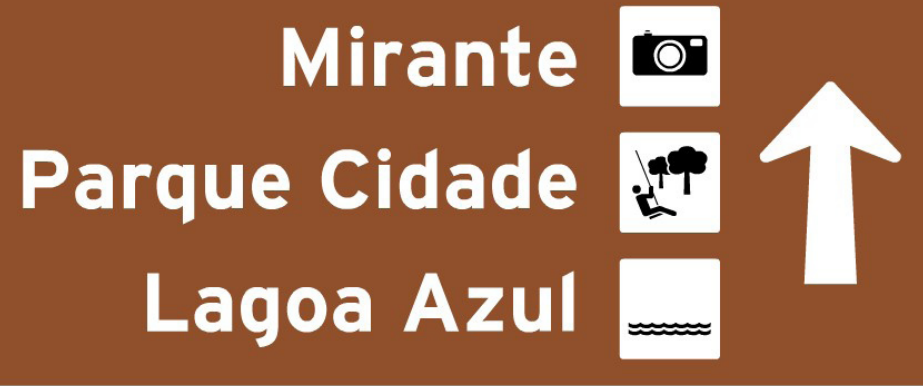


Fonte: <http://aimore.net/placas/placa_Atr_turistico_7.html >. Recuperado em 19 set. 2012.

Devido às peculiaridades históricas, culturais, sociais e ambientais de cada localidade, torna-se muito difícil a implantação de um sistema-padrão. As estratégias para a inserção de um sistema de sinalização devem, portanto, ser adaptadas as especificidades locais.

\section{A ATIVIDADE TURÍSTICA NO INTERIOR DO RIO GRANDE DO NORTE: CURRAIS NOVOS EM FOCO}

No Estado do Rio Grande do Norte, assim como em todo o Nordeste brasileiro, o turismo de sol e mar aparece como principal alternativa de exploração da atividade turística (Taveira; Fonseca, 2009), o que se deve ao seu vasto litoral, com especial atenção aos municípios que compõem o Polo Costa das Dunas, principal destino de turistas internacionais e nacionais em visita ao território potiguar. Contudo, existe o incentivo a diversificação da oferta por meio da interiorização da atividade turística. O território potiguar conta, atualmente, com cinco polos turísticos, dois quais três no interior do Estado (Polo Agreste/ Trairi; Polo Seridó e Polo Serrano).

Entre os polos do interior, o de maior destaque é o Polo Seridó, com um considerável potencial turístico a ser explorado por diversos segmentos, como o turismo cultural, religioso, pedagógico, eventos, aventura, ecoturismo, geoturismo entre outros. De acordo com o Serviço Brasileiro de Apoio às Micro e Pequenas Empresas do Rio Grande do Norte (SEBRAE/RN, 2006, p. 2): "A vegetação, topografia e clima, fauna e flora diferenciadas, aliadas à formação histórica do seu povo, criaram uma rica cultura, cujo conjunto tem enorme potencial para se transformar em excelente produto turístico."

Participante do roteiro turístico do Seridó, o município de Currais Novos, local desta pesquisa, além de inúmeros atrativos naturais e de um calendário anual de eventos importantes, dispõe de um patrimônio histórico e cultural singular, expresso tanto nas formas arquitetônicas (civil e religiosa) bem como nas expressões folclóricas, no artesanato local, na religiosidade do seu povo, entre outros fatores, o que atribui à cidade um relevante potencial turístico. 
Para desenvolver o turismo, Currais Novos, assim como os demais municípios que pretendem desenvolver a atividade, precisa planejar e preparar-se para receber o visitante, seja ele turista de eventos ou de outros segmentos. Visto que a cidade dispõe de um patrimônio histórico-cultural identificado por meio de atrativos como igrejas, praças, fundação cultural, casa de cultura, monumentos arquitetônicos e outros pontos de interesse turístico, tornam-se necessárias estratégias que busquem facilitar a circulação do turista pelo espaço urbano, sendo imprescindível a implantação de sinalização de orientação turística que esteja de acordo com os padrões nacionais e internacionais.

O município de Currais Novos encontra-se localizado no Estado do Rio Grande do Norte, situado na Mesorregião Central Potiguar e na Microrregião do Seridó Oriental, distante 172 Km da Capital Natal. Segundo o IBGE (2010), conta com uma população residente de 42.652 habitantes distribuídos em uma área total de $864,344 \mathrm{Km}^{2}$.

De acordo com o novo Mapa do turismo brasileiro, edição 2016, Currais Novos se encontra na categoria C, caracterizando-se como destinopredominantemente doméstico. Segundo as estimativas, turistas internacionais representam em média $1 \%$ do total de visitantes (Figura 4).

Figura 4 - Categoria de Currais Novos de acordo com o Mapa do turismo brasileiro.

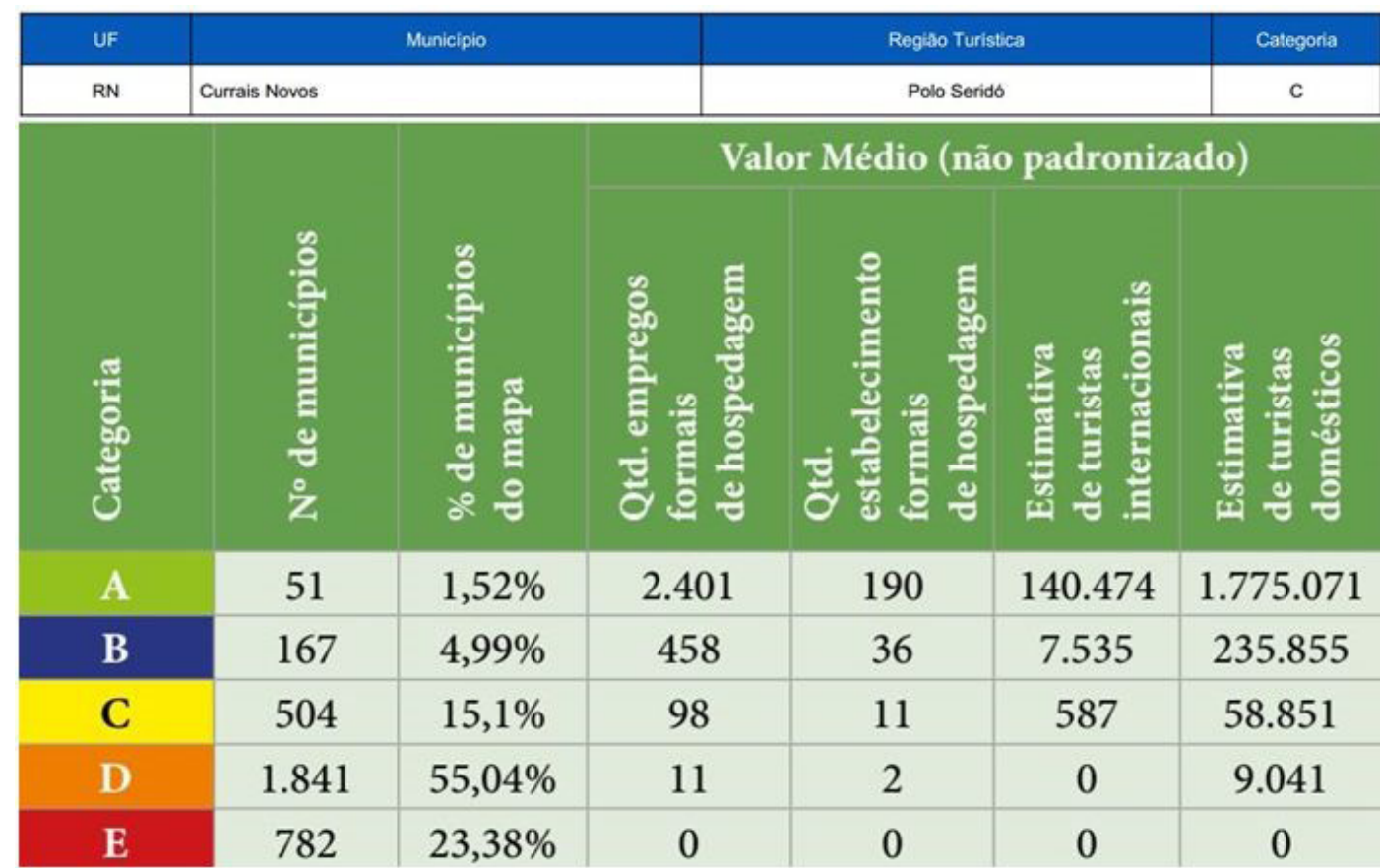

Fonte: Autor. Adaptado de Mtur (2016). Disponível em: <http://www.mapa.turismo. gov.br/mapa/downloads/pdf/categorizacao/Cartilha_da_Categorizacao.pdf $>$. Recuperado em: 21 ago. 2016. 
Currais Novos apresenta potencialidades para a exploração de diversos segmentos, como o geoturismo, com os geosítios Totoró e Apertados; ecoturismo, com a possibilidade de trilhas e outras atividades relacionadas; turismo de aventura, com cicloturismo, rapel; turismo de eventos, visto que possui um calendário anual; além do turismo cultural, com a possibilidade de visitação a monumentos, praças, fundação cultural, entre outros.

\section{METODOLOGIA}

A pesquisa consistiu em uma análise acerca da sinalização de orientação turística da área urbana de Currais Novos/RN, onde o nível de influência que a mesma exerce no deslocamento dos turistas que visitam a cidade. Inicialmente realizou-se a pesquisa bibliográfica, foram pesquisados dados oficiaisdisponíveis em meio eletrônico, de órgãos públicos, como Ministério do Turismo (MTur), Instituto Brasileiro de Turismo (EMBRATUR), Departamento Nacional de Trânsito (DENATRAN) e Conselho Nacional de Trânsito (CONTRAN). A pesquisa de campo se dividiu em dois momentos, onde, primeiro, realizou-se o levantamento de toda a sinalização de orientação turística existente na área urbana de Currais Novos, visando conhecer a abrangência da área a ser estudada; Posteriormente, buscando compreender o que o turista pensa a respeito da sinalização de orientação turística e como esta influencia nos deslocamentos pela cidade, aplicou-se a coleta de dados por meio de formulário semiestruturado com um total de 12 questões.

Visando coletar dados de grupos distintos de visitantes, o formulário foi aplicado em dois momentos distintos. Durante os dias 7, 8 e 9 de setembro de 2012, com turistas de eventos, em decorrência da $17^{a}$ edição do Carnaxelita, micareta que acontece todos os anos desde 1996 no mês de setembro. No segundo momento, entre os dias 1 e 5 de outubro de 2012, aplicado com os turistas de negócios, correspondendo ao grupo de pessoas que vêm a Currais Novos por motivo de negócios e afins, mas que também utilizam os serviços e equipamentos turísticos disponíveis. Aamostra colhida compreendeu um total de 68 entrevistados. Destes $81 \%$ apontaram a sinalização turística como importante. No período da pesquisa não foram encontrados turistas internacionais para 
compor a amostragem o que evidencia o público notadamente de turista doméstico no município.

Com o levantamento das placas indicativas e posterior aplicação de formulário semiestruturado com grupos específicos de turistas, chegou-se a conclusão de que a sinalização contribui, embora parcialmente na maioria dos casos, para o deslocamento no espaço urbano do município. Contudo, segundo afirmam os próprios entrevistados, o aumento do número de placas indicativas proporcionaria um deslocamento mais eficiente e consequentemente um maior consumo dos atrativos urbanos da cidade de Currais Novos/RN.

\section{ANÁLISE DOS RESULTADOS: A SINALIZAÇÃO DE ORIENTAÇÃO TURÍSTICA EM CURRAIS NOVOS/RN}

Um fato relevante identificado na coleta de dados diz respeito a que meio de transporte que o turista utiliza para se locomover pela cidade de Currais Novos. Conforme indicado no Gráfico 1, a maioria dos turistas fazem uso de algum tipo de veículo para transporte, sendo o automóvel próprio o mais utilizado, seguido do serviço de moto táxi. Ainda existe uma parcela considerável de turistas que se locomove a pé pela cidade.

Gráfico 1 - Como o turista se desloca pela cidade de Currais Novos.

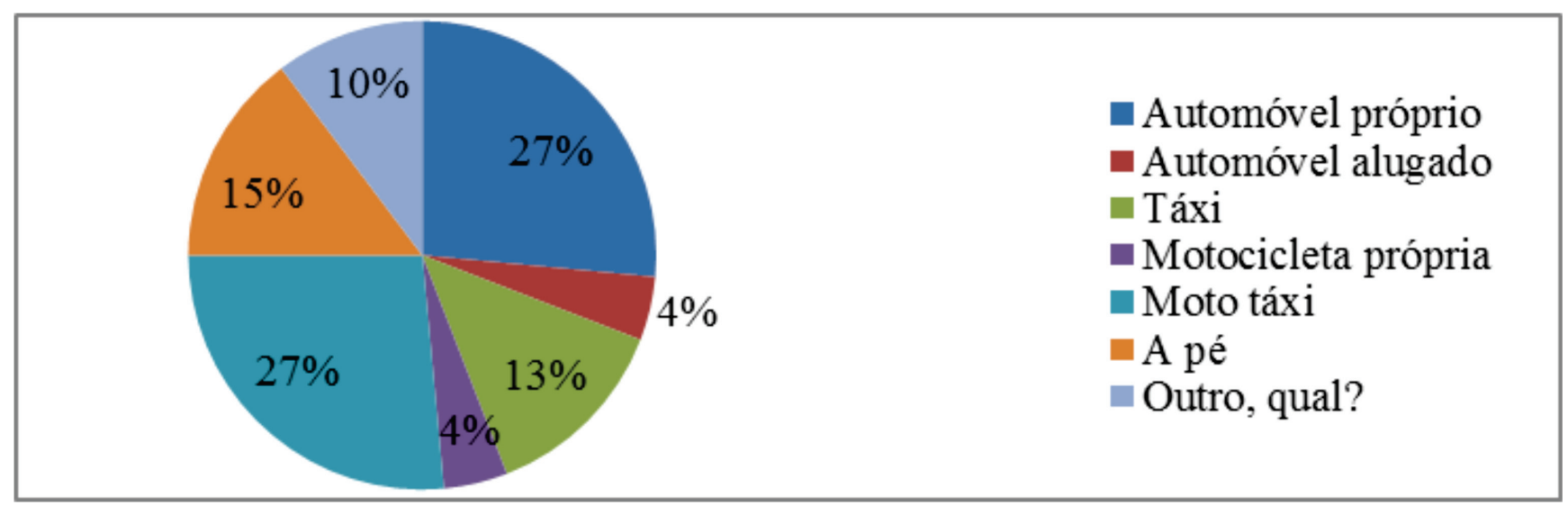

Fonte: Pesquisa de campo, 2012.

Entre a amostra pesquisada, apenas 31\% visitavam Currais Novos pela primeira vez, enquanto o restante (69\%) já conhecia a cidade. Também observouse a baixa utilização da sinalização de orientação turística de Currais Novos é considerada baixa, visto que apenas $16 \%$ dos turistas entrevistados fizeram uso das placas para auxílio nos deslocamentos. 
Entretanto, torna-se importante ressaltar que, conforme a tabela 2, a utilização da sinalização é maior entre os turistas que realizam a primeira visita à Currais Novos quando comparado com os que já estão em sua segunda ou mais visitas, onde a necessidade desse tipo de orientação é mais dispensável. Quanto a estes, a maioria diz ter feito uso de outro tipo de orientação como um complemento à sinalização para se locomover pela cidade, como por exemplo, parou para perguntar, seguiu a dica de um amigo, já conhecia o lugar, entre outros.

Tabela 2 - Relação de turistas que utilizaram a sinalização de orientação turística segundo o número de visitas a Currais Novos

\begin{tabular}{c|ccc|c}
\hline \multirow{2}{*}{$\begin{array}{c}\text { Uso da sinalização de } \\
\text { orientação turística }\end{array}$} & \multicolumn{2}{|c|}{ Turistas } & \multirow{2}{*}{ Total } \\
\cline { 2 - 3 } & $1^{\text {a }}$ vez na cidade & $2^{\text {a }}$ ou mais vezes na cidade & $11(16,0)$ \\
Utilizou (\%) & $6(29,0)$ & $5(11,0)$ & $57(84,0)$ \\
Não utilizou (\%) & $15(71,0)$ & $42(89,0)$ & $68(100,0)$ \\
\hline Total de turistas (\%) & $21(31,0)$ & $47(69,0)$ & \\
\hline
\end{tabular}

Fonte: Pesquisa de campo, 2012.

Entre os que fizeram uso das placas de sinalização de orientação turística, a maioria é composta por homens (73\%). Já quando comparado com o total de entrevistados, observa-se apenas $20 \%$ dos indivíduos do sexo masculino e $11 \%$ do sexo feminino. Todavia, no tocante ao quesito suficiência das informações no auxílio dos deslocamentos, a avaliação foi positiva (Gráfico 2), confirmando que as placas de sinalização estão de acordo com os sete princípios básicos do sistema de sinalização, que são: Legalidade; Padronização; Visibilidade, legibilidade e segurança; Suficiência; Continuidade e coerência; Atualidade e valorização; Manutenção e conservação.

Gráfico 2 - Auxílio da sinalização de orientação turística nos deslocamentos pela cidade de Currais Novos/RN.

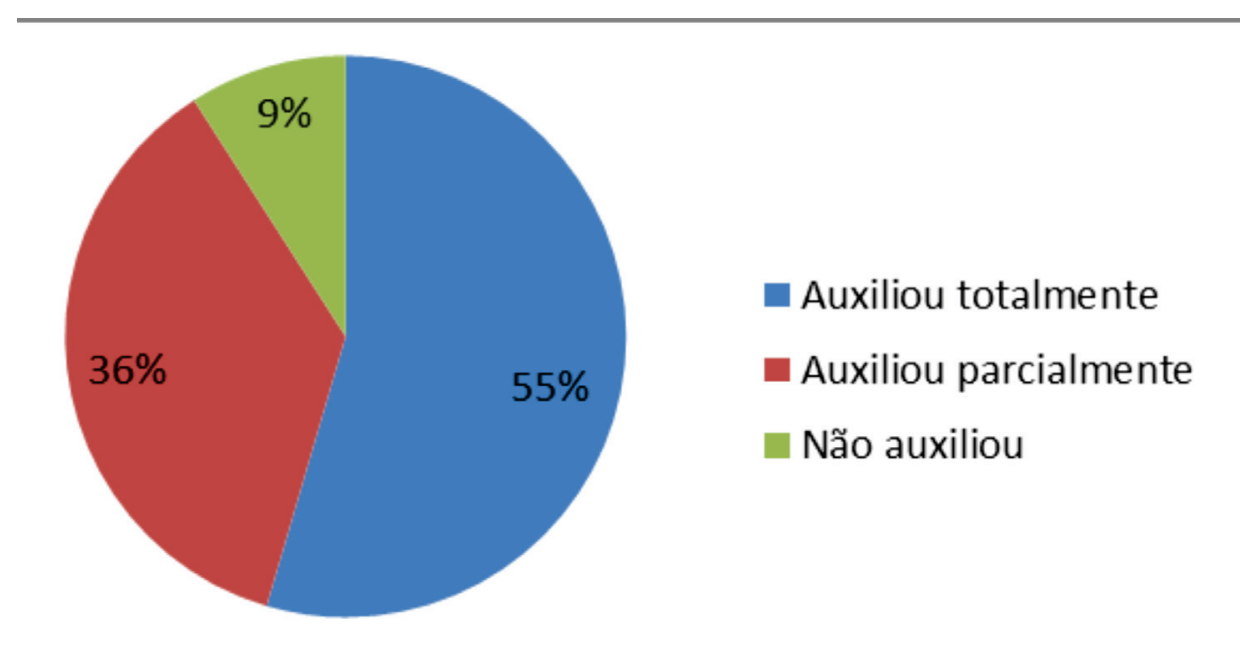


Fonte: Pesquisa de campo, 2012.

A pesquisa aponta que o visitante compreende a importância da sinalização de orientação turística no auxílio aos deslocamentos nos destinos turísticos. Tal fato se revela a partir do gráfico 3 , onde a maioria a considera como um item importante nos destinos, conforme $81 \%$ dos entrevistados.

Finalmente, levantaram-se críticas e sugestões dos visitantes acerca da sinalização existente e as respostas mais comuns dizem respeito ao baixo número de placas na cidade, o que dificulta tanto a locomoção até os atrativos a que se pretende visitar quanto o conhecimento de novos atrativos que seria possibilitado por meio das informações das placas. Segundo os entrevistados, um maior número de placas melhoraria a qualidade das informações bem como o acesso até os pontos de interesse.

Percebe-se a partir dos dados apresentados que a sinalização de orientação turística de Currais Novos apresenta deficiências, atendendo apenas parcialmente as necessidades dos turistas, sendo necessário o uso de outros meios e instrumentos para que possam se locomover pela cidade e chegar às localidades pretendidas. Em suma, a sinalização não é utilizada como o único instrumento de auxílio, mas um entre vários meios que servem para a tomada de decisão no deslocamento do turista.

\section{SITUAÇÃO DA SINALIZAÇÃO DE ORIENTAÇÃO TURÍSTICA DA ÁREA URBANA DE CURRAIS NOVOS}

Analisar a situação existente da sinalização de orientação turística de qualquer área urbana não é tarefa simples. Visando garantir a homogeneidade e eficácia, é exigida do pesquisador uma avaliação que contemple os sete princípios básicos do sistema de sinalização.

Nesta pesquisa é dispensado avaliar o princípio de legalidade, visto que não cabe aqui questionar a legislação nem tampouco os detalhes sobre regras e normas de trânsito vigente para comparar com a sinalização de orientação turística da cidade de Currais Novos (Figura 5). Quanto ao princípio de atualidade e valorização, é explicado na totalidade da análise da sinalização local. 
Figura 5 - Padronização das placas de sinalização de orientação turística da cidade de Currais Novos/RN.

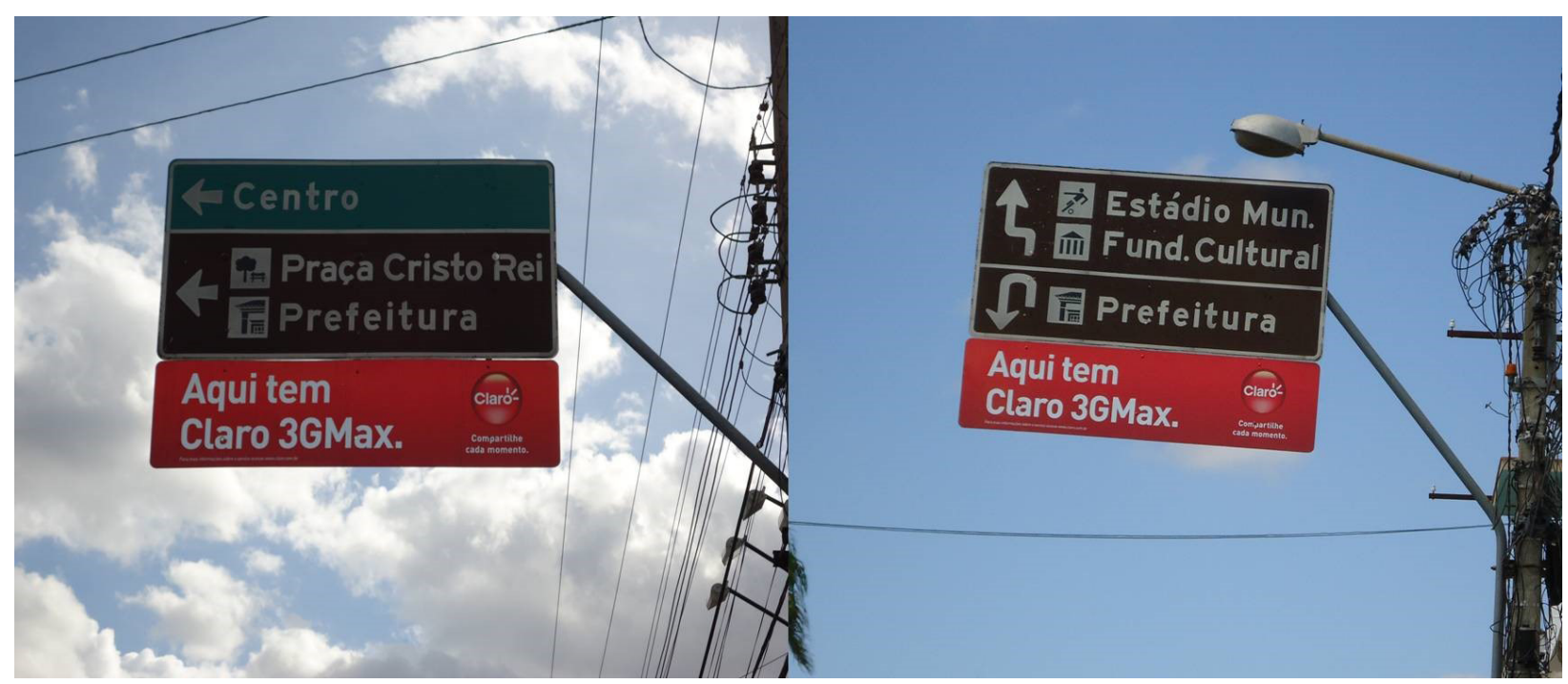

Fonte: Acervo do autor, 2012.

Averígua-se que a sinalização de orientação turística existente na cidade de Currais Novos atende a maioria dos quesitos dos princípios básicos do sistema de sinalização, conforme segue:

Obedece aos princípios da sinalização turística quanto a:

- Padronização: Segue o Padrão utilizado pelo Guia Brasileiro de Sinalização Turística, o qual está de acordo com a resolução de 1996 do CONTRAN, que instituiu o uso da cor marrom para sinalização turística. Utiliza-se a mesma fonte para as letras, o alfabeto série (EM). As setas direcionais assim como os pictogramas também estão em consonância com o previsto no referido guia.

- Visibilidade, legibilidade e segurança: afixadas em lugares altos, não havendo árvores ou outro obstáculo obstruindo a visão do turista, podem ser visualizadas e lidas a uma distância segura, tanto para turistas a pé quanto para motorizados.

- Suficiência: Oferecem informações indispensáveis a fim de atender os deslocamentos dos usuários.

- Conservação: As placas localizadas na Avenida Dr. Sílvio Bezerra e na Rua Cap. Mor Galvão (Figura 5) encontram-se em bom estado de conservação. Entretanto, a sinalização que se encontrava na Avenida Getúlio Vargas oferecia risco aos passantes, estando a com placa se soltando do poste. A mesma foi retirada do local e até o término desta pesquisa não houve a substituição. 
Não obedece aos princípios da sinalização turística quanto a:

- Continuidade e coerência: percebe-se a existência de falha na sinalização de orientação turística que indica o Estádio Municipal Coronel José Bezerra. A seta direcional deveria indicar tanto o Estádio Municipal como a Fundação Cultural José Bezerra Gomes, entretanto ela só aponta de fato a localização deste último (Figura 6), necessitando de outra placa para indicar a direção do estádio de futebol.

Figura 6 - Falha no critério de continuidade e coerência na sinalização de orientação turística de Currais Novos.

\section{Legenda}
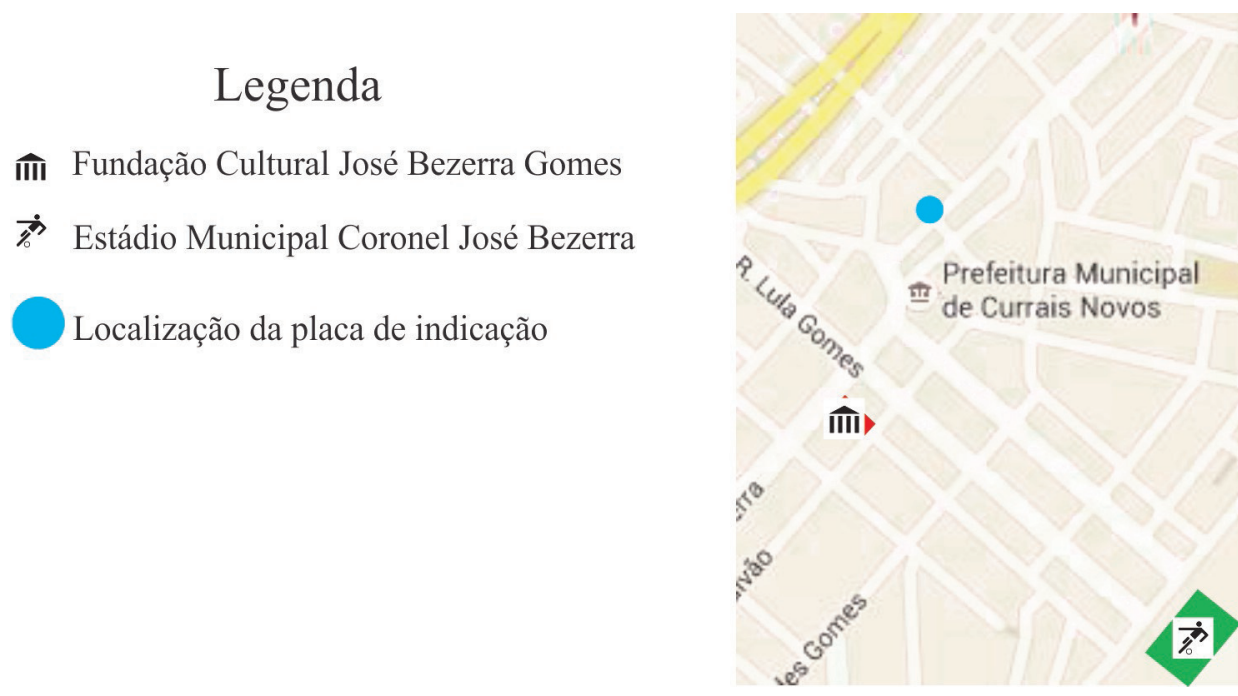

Fonte: Google Maps, 2010. Adaptado pelo autor, 2012.

A área urbana do município de Currais Novos possui atualmente apenas duas placas de sinalização que estão em conformidade com alguns dos critérios indicados pelo Guia Brasileiro de Sinalização Turística, sendo considerado insuficiente e que atende somente a alguns atrativos localizados no centro da cidade, deixando outros pontos de interesse desprovidos, sem fazer uso de qualquer tipo de ferramenta para informação e orientação de turistas.

Portanto, entende-se que verificar a situação atual da sinalização de orientação turística de Currais Novos se torna de suma importância visto que, por meio deste levantamento, podem-se elaborar as estratégias e consequentes propostas para a sinalização viária de indicação turística da cidade.

Não é intuito da pesquisa propor um projeto de sinalização de orientação turística para a cidade de Currais Novos. No entanto, torna-se pertinente mostrar, como a sua implantação poderia otimizar a circulação de turistas pela 
cidade. Salienta-se que neste exemplo não são enfocados parâmetros técnicos como detalhamentos, materiais, dimensões, posicionamento e/ou suporte das placas, mas sim ressaltados conceitos gerais que condizem com os objetivos e princípios básicos da sinalização, conforme já apresentados nesta pesquisa.

$\mathrm{Na}$ inexistência de estudos a respeito da hierarquização dos atrativos turísticos, foram elencados, de maneira empírica, pontos da área urbana no município mais citados em sites, livros e artigos, o que não esgota a possibilidade de que outras áreas não possam ser citados em futuros projetos de sinalização para Currais Novos.

Foram estabelecidos um total de sete placas dispostas ao longo do percurso que leva aos 15 pontos de interesse do turista (Figura 7), contemplando um total de 6 bairros de Currais Novos. O trajeto foi elaborado para o turista que chega à cidade pela BR 226, no sentido Natal/interior, conforme figuras 8, 9 e 10.

Figura 7 - Localização dos pontos de interesse turístico indicados nas placas de sinalização de orientação turística na área urbana de Currais Novos/RN.

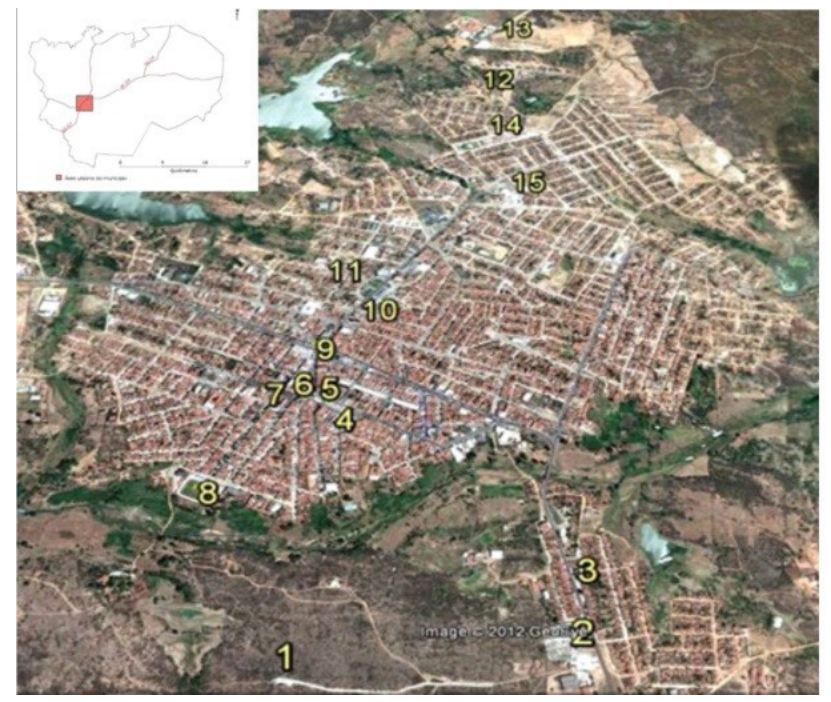

\author{
Pedra do Navio \\ Praça do Calvário \\ Praça Aproniano Pereira \\ Igreja Matriz de Santana \\ Praça Cristo Rei \\ Prefeitura Municipal \\ Fundação Cultural José Bezerra Gomes \\ Estádio Municipal Coronel José Bezerra \\ Centro de Artesanato e Culinária de Currais Novos \\ Rodoviária \\ Praça Tetê Salustino \\ Parque de Exposições Agropecuárias José B. de Araújo \\ Parque de Vaquejada Dr. Sílvio Bezerra de Melo \\ Praça Largo Jr. Toscano \\ Espaço Cultural Mons. Ausônio de Araújo
}

Fonte: Base Cartográfica do IBGE, mapa municipal estatístico, 2010 e recorte de imagem do Google Earth, 2012.

Na figura 8, a placa está localizada a margem direita da Avenida 13 de Maio, no sentido centro, sendo indicados três atrativos, a Pedra do Navio, que embora se situe fora da área urbana, por estar muito próxima a ela e pelo seu apelo turístico é indicada na sinalização, e as praças do Calvário e Aproniano Pereira.

Figura 8 - Placa $n^{\circ} 1$ com indicação dos pontos de interesse turístico da área urbana de Currais Novos 


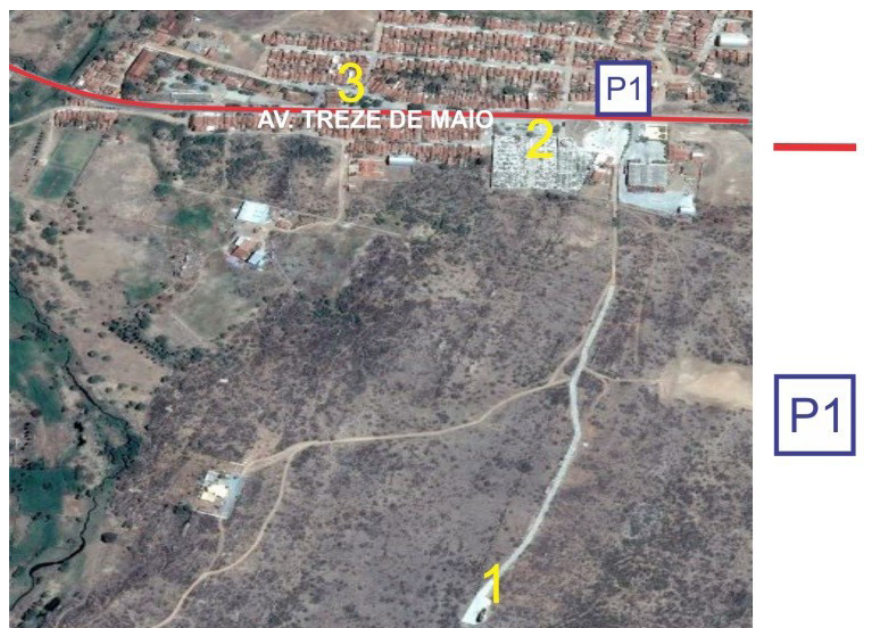

Vias Principais

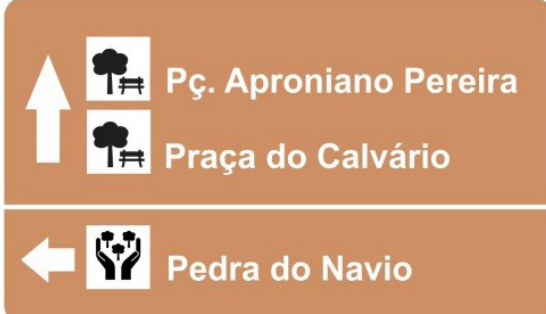

Fonte: Google Earth. Adaptado pelo autor, 2012.

$\mathrm{Na}$ análise da figura 9, quatro placas direcionam para oito pontos de interesse. A placa $n^{\circ} 2$ (P2), localizada no início da Avenida Dr. Sílvio Bezerra, orienta o turista tanto a seguir em frente, caso queira visitar o Centro de Artesanato e Culinária de Currais Novos, ou a esquerda, caso prefira visitar a Praça Cristo Rei, a Matriz de Santana e/ou a Prefeitura. A placa n³ 3, na Rua Cap. Mor Galvão, é um complemento da $n^{\circ} 2$ aos três últimos atrativos citados. Situada na esquina entre a Avenida Cel. José Bezerra e a Rua Juventino da Silveira, a placa $n^{\circ} 4$ indica a localização da Fundação Cultural José Bezerra Gomes e do Estádio Municipal Coronel José Bezerra. Já a placa nº 5 está disposta entre a Avenida Dr. Sílvio Bezerra e a Rua Teotônio Freire, indicando a localização da Rodoviária e da Praça Tetê Salustino.

Figura 9 - Placas $n^{\circ}$ 2, 3, 4 e 5 com indicação dos pontos de interesse turístico da área urbana de Currais Novos.

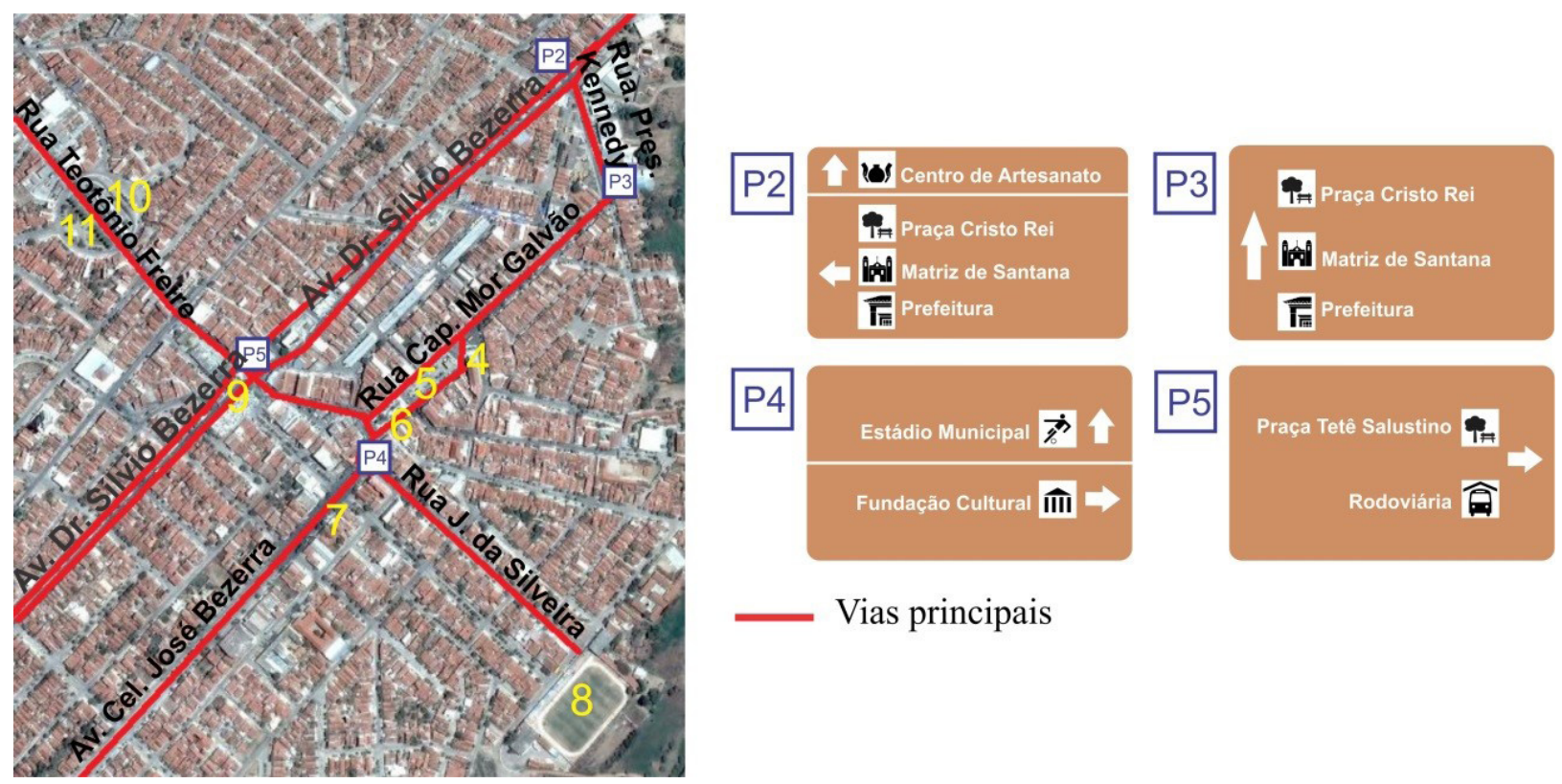

Fonte: Google Earth. Adaptado pelo autor, 2012. 
Na figura 10, quatro pontos de interesse são indicados por duas placas. A placa $n^{\circ}$ 6, entre as ruas Teotônio Freire e Stuessel Augusto indica o Espaço Cultural Mons. Ausônio de Araújo, a Praça Largo Júnior Toscano, o Parque de Exposições Agropecuárias José Bezerra de Araújo e o Parque de Vaquejada Dr. Sílvio Bezerra de Melo. A placa $n^{\circ} 7$, situada no encontro das Ruas Teotônio Freire e Rua do Petróleo aponta para os três últimos atrativos citados.

Figura 10 - Disposição das placas $n^{\circ} 6$ e 7 com indicação dos pontos de interesse turístico da área urbana de Currais Novos.

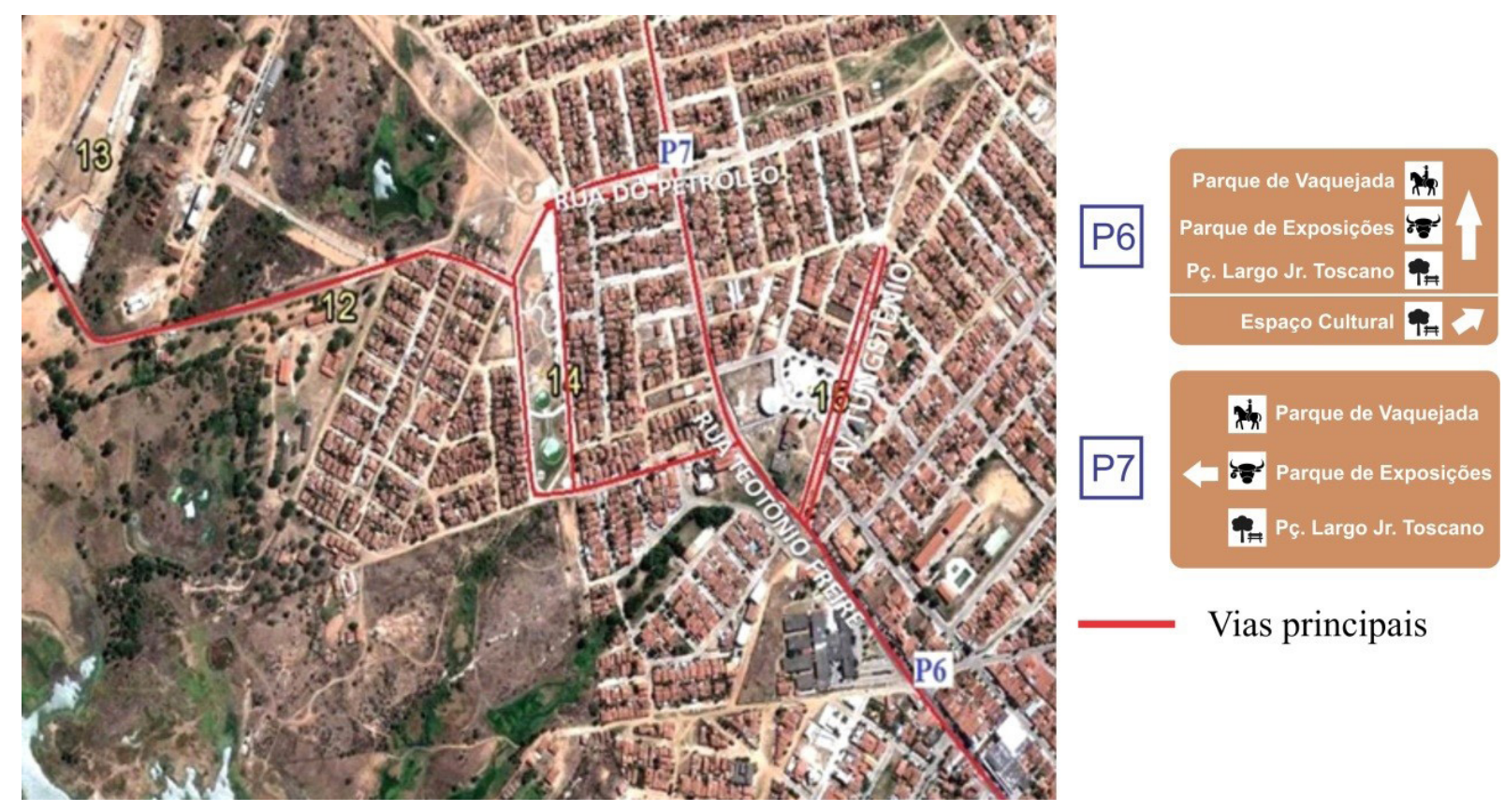

Fonte: Google Earth. Adaptado pelo autor, 2012.

Como se pode notar, no modelo apresentado é possível verificar o efeito positivo que a sinalização de orientação turística pode trazer para o turismo da cidade, é possível notar que por meio do princípio de continuidade das placas, todos os pontos de interesse existentes são contemplados no trajeto, facilitando assim o deslocamento do turista e otimizando o tempo desprendido entre a saída do local onde se está até achegada ao local pretendido.

\section{CONSIDERAÇÕES}

O tema sinalização e mais especificamente sinalização de orientação turística ainda é pouco explorado por pesquisadores e acadêmicos do turismo, tornando este estudo relevante por seu ineditismo e tentativa de compreensão de como tal instrumento interfere na dinâmica dos destinos. 
Por meio da pesquisa, constatou-se que a sinalização de orientação turística utilizada na cidade de Currais Novos/RN atende parcialmente a necessidade dos turistas, fazendo-se necessário, em grande parte dos casos, a utilização de outros meios de informação, como a dica de parentes e amigos ou mesmo a solicitar ajuda aos residentes.

Acredita-se que a baixa influência da sinalização nos deslocamentos dos turistas em Currais Novos/RN, sobretudo para os que já a visitaram mais de uma vez, se dá, em parte, pelo porte da cidade, onde em um único dia se pode percorrer toda a sua extensão à pé, o que facilita a apreensão dos seus traços marcantes, tornando, em determinadas ocasiões, dispensável o uso de placas com fins de orientação turística.

Existe, ainda, a necessidade de ampliação do número de placas de sinalização de orientação turística na área urbana do município, visto que, conforme os próprios entrevistados, facilitaria o deslocamento bem como proporcionaria a chance de conhecer uma gama maior de atrativos turísticos. Assim, como consequência de um deslocamento eficiente, o maior tempo livre poderia estimular o consumo de um número maior de produtos e serviços, beneficiando o turismo local.

Em razão da necessidade de se fazer com que o turista chegue ao local pretendido faz com que a sinalização de orientação turística se torne mais evidente do que a sinalização interpretativa. De nada adianta a instalação deste tipo de placa no atrativo se o turista, em muitas ocasiões, não sabe como chegar, ou desconhece sua existência. Contudo, por meio das instruções das placas indicativas o visitante passa a tomar conhecimento de novos lugares, podendo instigar a sua visitação.

Recomenda-se que os gestores do turismo atentem ao fato de que a sinalização deve ser universal, atendendo, portanto, a indivíduos de diferentes nacionalidades, culturas, níveis sociais e/ ou de escolaridade. Portanto, a sinalização deve atingir sua finalidade máxima, que é gerar a rápida e fácil interpretação dos sinais.

Para tanto, torna-se indispensável o entendimento de que, mesmo que se busque empregar traços regionais do destino turístico na sinalização, esta deve seguir critérios internacionais e globais, visando à universalidade, visto que o turismo é um fenômeno social mundial. 
Por fim, ressalta-se como limitante desta pesquisa, o número reduzido de fundamentação teórica sobre o tema que reflete em poucos trabalhos publicados na área sobre o tema sinalização turística, que é um item importante, não apenas no campo técnico, mas no planejamento de cidades e regiões turísticas. Fica, pois, evidente a necessidade de mais pesquisas, tornando possíveis os estudos comparativos com a finalidade de aperfeiçoar o planejamento do turismo.

\section{REFERÊNCIAS}

Bissoli, M.A.M.A. (2002). Planejamento turístico municipal com suporte em sistemas de informação. 3. ed. São Paulo: Futura.

Brasil. (2016). MINISTÉRIO DO TURISMO. Categorização dos municípios das regiões turísticas do mapa do turismo brasileiro. Recuperado em 21 de agosto, http://www.mapa.turismo.gov. $\mathrm{br} / \mathrm{mapa} /$ downloads/pdf/categorizacao/Cartilha_da_Categorizacao.pdf.

Equador. (2016). MINISTÉRIO DE TURISMO. Manual de señalización turística. 2007, Recuperado em 22 de agosto, https://jorgepaguay.files.wordpress.com/2011/10/manualsec3b1alizacic3b3n-25-08-2011.pdf.

EMBRATUR; IPHAN; DENATRAN. (2012). Guia Brasileiro de Sinalização Turística. Recuperado em 20 de agosto, de http://www.bancodevideos.turismo.gov.br/guia/conteudo/principal.html.

Hall, C. M. (2001). Planejamento Turístico: políticas, processos e planejamentos. São Paulo: Contexto.

IBGE. (2012). Instituto Brasileiro de Geografia e Estatística. Currais Novos/RN. Recuperado em 20 de agosto, de http://www.ibge.gov.br/cidadesat/topwindow.htm?1.

Marujo, M. N.; Carvalho, P. (2010). Turismo, planeamento e desenvolvimento sustentável. Turismo \& Sociedade, Curitiba, v. 3, n. 2, p. 147-161 Recuperado em 22 de agosto, 2012 de http://ojs.c3sl.ufpr.br/ojs2/index.php/turismo/article/view/19635/12832.

OMT. (2003). Organização Mundial do Turismo. Sinais e Símbolos Turísticos: guia ilustrado e descritivo. Tradução de Gabriela Scuta Fagliari. São Paulo: ROCA.

Ruiz, T. C. D.; Gandara, J. M. G. (2013). A Relação entre o Planejamento Urbano e a Competitividade dos Destinos Turísticos. Revista Brasileira de Pesquisa em Turismo. São Paulo, v. 7, n. 2, p. 260-280, maio/ago. 2013. Recuperado em 05 de setembro, de http:// www.rbtur.org.br/rbtur/article/view/555/609.

Santaella, L. (2007). O que é semiótica. São Paulo: Brasiliense. 
Scatolin, K. et al. (2006). Sinalização Turística Interpretativa e Indicativa: um estudo de caso do centro velho da cidade de São Paulo. São Bernardo do Campo, SP: UMESP, 2006. 109 p. Recuperado em 13 de setembro, de http://www.vivaocentro.org.br/noticias/arquivo/TCC_ Sinal_Tur.pdf.

SEBRAE. (2006) Serviço Brasileiro de Apoio às Micro e Pequenas Empresas. Pólo Turístico do Seridó: guia do investidor no setor turístico. Natal, 180 p. Recuperado em 21 de setembro, 2012, de www.roteiroserido.com.br/turismo/guia_investidor/21.

Souza, M.E.A. (2006). Sinalização turística e percepção do espaço geográfico. Turismo Visão e Ação, Itajaí, V. 8, n. 1, p. 165 - 176, jan. Recuperado em 12 de setembro, 2012, de http://www6.univali.br/seer/index.php/rtva/article/view/504/0.

Taveira, M. da S.; Fonseca, M. A. P. da. (2009) O modelo turístico potiguar e seus efeitos socioespaciais nas comunidades litorâneas. Revista acadêmica Observatório de Inovação do Turismo, v. IV, p. 1-13, Recuperado em 20 de setembro, 2012, de http://bibliotecadigital.fgv. br/ojs/index.php/oit/article/view/5755/4467.

\section{Contribuição dos autores na construção do artigo \\ Nascimento: Pesquisa e desenvolvimento do trabalho França: Orientação e desenvolvimento do trabalho}

